\title{
Telomeres And Early Life Stress: A Review
}

\author{
Dr. Th. Bihari Singh ${ }^{1}$,Dr. Niranjan Hebbar Y.R. ${ }^{2}$,Dr. Udayan Majumder ${ }^{3}$, \\ Dr. Ashutosh Dash ${ }^{4}$ \\ ${ }^{1}$ Professor ${ }^{2,3,4}$ Post Graduate Trainees \\ Department Of Psychiatry, Regional Institute Of Medical Sciences, Imphal, Manipur
}

\begin{abstract}
Last few years there is an evidence of increasing studies done on impact of early life stress and associated morbidities in later life. One such association was to assess the impact of psychological stress with respect to ageing. Shorter telomere length is associated with advancing chronological age and also increased disease morbidity and mortality. In this review, we try understanding about telomeres, early life adverse events, stress and coping skills and lastly, highlighting the recent empirical evidence linking stress exposure during childhood with telomere shortening.
\end{abstract}

Keywords: Telomeres, early life stress, epidemiology, pathophysiology

\section{Stress, Coping And Aging}

Individuals differ in their psychological and biological responses to stress. In particular, an individual's appraisal or assessment of a specific psychological stressor determines their cognitive-emotional response, which in turn influences their biological response and hence the extent to which the stressor has the potential to "get under the skin" to influence physical health. ${ }^{1}$ According to the classic Lazarus and Folkman "Transactional Model of Stress and Coping", individuals who perceive that a stressor exceeds their resources to cope effectively will appraise the situation as threatening and exhibit a response characterized by threat-related cognitions and emotions such as worry and fear. In contrast, individuals who perceive that they have adequate resources to cope with a stressor will appraise it as challenging and exhibit a response characterized by challenge related cognitions and emotions such as perceived control and excitement. ${ }^{2}$

Subsequent research has shown that biological reactions to stressors appraised as threatening differ from those appraised as challenging, and that the former are associated with more harmful physiological reactions than are the latter. The biological response to stress involves the coordinated activity of several systems, including the hypothalamic-pituitary-adrenal (HPA) axis, the sympathetic nervous system, and the immune system. Acute activation of these systems serves to mobilize energy resources and prepare the individual for coping with stressors. With chronic stress exposure, however, attempts at adaptation can result in pathological perturbation of endocrine, immune, and metabolic systems.,

There is possibility that certain psychiatric illnesses are associated with accelerated biological aging at cellular level. Whereas chronological age is measured in calendar units, biological age is defined physiologically and is more closely associated with disease processes. "Accelerated biological aging" occurs when biological age outpaces chronological age.

\section{Telomeres}

Telomeres (from the Greek telos [end] and meros [part]) are DNA-protein complexes at the ends of chromosomes, composed of tandem TTAGGG repeats ranging from a few to 15 kilobases in length mainly protecting chromosomes from damage. Telomeres shorten with repeated cell divisions in somatic cells due to incomplete replication of the telomere ends, replication and nuclease-associated telomeric DNA damage, and/or chronic exposure to oxidation, certain cytotoxins or inflammation and possibly chronic exposure to the stress hormones, cortisol and catecholamine. ${ }^{5}$ When telomeres reach a critically short length, cells undergo replicative senescence or can become genomically unstable.

Leukocyte telomere length generally decreases progressively over the lifespan, with estimates of average attrition rate ranging between 14 to 103 base pairs (bp) per year (weighted mean of 21.9 bp per year) in cross-sectional studies, and between 32.2 to $45.5 \mathrm{bp}$ per year (weighted mean of 40.7 bp per year) in longitudinal studies. ${ }^{7}$ Some individuals maintain and may even lengthen average LTL for some periods. The reasons for this are unknown, but relatively long telomeres tend to shorten over time, and relatively short telomeres tend to lengthen over time, possibly due to the preferential recruitment of reparative mechanisms such as telomerase activity (TA). ${ }^{8}$

Telomere length can be maintained by the enzyme telomerase, a ribonucleoprotein reverse transcriptase mainly expressed in stem cells, germ cells, and regenerating tissues. However, there is insufficient telomerase in somatic cells to indefinitely maintain telomere length, and most tissues have very low telomerase levels. 
Consequently, telomeres shorten with age in most somatic tissues, and telomere length can serve as a kind of biological counter, ticking off the passage of time with each cell division. ${ }^{9}$ Telomere shortening is also influenced by recombination, epigenetic regulation, and genetic factors, as well as oxidative stress, and the ability of telomerase to counteract these influences is limited. There are some studies linking shorter LTL with premature mortality. ${ }^{10}$

\section{Telomeres And Stress}

Chronic or excessive activation of these stress-responsive systems may also result in telomere shortening. In replicating somatic cells, telomeres shorten progressively with each cell division, ultimately leading to replicative senescence, and exposure to stressors can hasten telomere shortening and lead to premature cell senescence. ${ }^{11}$ Shortened leukocyte telomere length has been linked to morbidity and mortality of age-related illnesses. ${ }^{12,13}$ Several genes and proteins that regulate telomere length have been identified ${ }^{14}$, and telomere shortening is also induced by physiologic stressors such as exposure to radiation and toxins ${ }^{15}$, oxidative stress. ${ }^{16}$ Of particular relevance to psychiatric disorders are recent findings in humans of an association between psychological stress and shortened leukocyte telomere length.

\section{Telomeres and its relation with early life stress}

Rates of telomere shortening are fastest during infancy and early childhood ${ }^{17,18}$, and regulation of telomere length may be programmed in early development ${ }^{19}$. In humans, childhood maltreatment is a common form of early adversity, and is a major risk factor for a range of adverse outcomes, including major depression, anxiety disorders, and substance abuse ${ }^{20,21}$. That early life experiences have enduring sequelae has been a central tenet of psychiatry for over a century. Initial formulations of this idea emphasized clinical implications, particularly in classical psychoanalytic theory, and it is now well documented that childhood adversity increases risk for major depression (MDD), bipolar disorder, anxiety disorders, substance disorders, schizophrenia, eating disorders, personality disorders, and suicidality. ${ }^{22}$

More recently, an etiological role for early-life stress has been documented for several prevalent somatic conditions, including irritable bowel syndrome ${ }^{23}$, fibromyalgia $^{24}$, chronic fatigue syndrome ${ }^{25}$, obesity ${ }^{26}$, migraine $^{27}$, and chronic pain ${ }^{28}$. These disorders have in common an unclear, perhaps multi-factorial etiology and pathophysiology.

However, some investigators suggest that early environmental factors can also impact the risk for conditions generally thought to have a relatively clear pathogenesis, such as cardiovascular disease and type 2 diabetes $^{29}$. Indeed, individuals with a history of early life stress show increased risk for premature death, with one recent study reporting that adults with six or more adverse childhood experiences died nearly 20 years earlier than those without. ${ }^{30}$ Tyrka et al. ${ }^{31}$ offered the first evidence linking early-life stress with reduced telomere length, in a study of physically and psychiatrically healthy adults with $(\mathrm{N}=10)$ or without $(\mathrm{N}=21)$ a reported history of childhood maltreatment. Eight other studies have since appeared examining this issue, a remarkable number given the short time interval. In response to Tyrka et al., Glass et al. ${ }^{32}$ presented data on adults from the Twins UK cohort in which they detected no difference in telomere length between individuals who endorsed childhood sexual $(\mathrm{N}=34)$ or physical abuse $(\mathrm{N}=20)$ compared to those who did not $(\mathrm{N}=516$ and 520 , respectively). However, Kananen et al. ${ }^{33}$ confirmed an association of shorter telomere length with increasing number of reported childhood adverse life events in N=974 adults in the Finnish Health 2000 project, even absent a relationship with current psychological distress or anxiety disorder diagnosis. Kiecolt-Glaser et al ${ }^{34}$ reported that shorter telomeres were associated with multiple childhood adversities in a study comprising dementia family caregivers $(\mathrm{N}=58)$ and controls $(\mathrm{N}=74)$. Surtees et al. ${ }^{35}$, studying 4,441 women in the UK European Prospective Investigation into Cancer (EPIC)-Norfolk database, found that shorter telomeres correlated with increased reported childhood adverse experiences, although not with current social adversity or emotional health.

In the first study to show effects of early adversity on telomere length in children, Drury et al. ${ }^{36}$ found that greater time spent in institutional care correlated with reduced buccal cell telomere length in 100 children aged 6-10 years in the prospective Bucharest Early Intervention Project. Extending the period of vulnerability, Entringer et al. ${ }^{37}$ demonstrated that maternal experience of severe psychosocial stress during pregnancy was associated with shorter telomeres in young adult offspring $(\mathrm{N}=45)$ vs. controls $(\mathrm{N}=49)$. In the only prospective longitudinal study thus far, involving 236 children tested at age 5 and again at age 10 years.

However many subject-level variables, such as age, sex, genetic polymorphisms, "resiliency," education, history of early life adversities, parental responsiveness, socioeconomic status, health behaviors, diet, and latent or active viral infections (e.g., cytomegalovirus or herpes virus) may affect LTL, independent of the disease process being studied ${ }^{38-43}$. Other potentially important confounds in interpreting LTL in psychiatric illnesses are psychiatric and medical co-morbidities. Many psychiatric diagnoses has a high co-morbidity with secondary psychiatric illnesses such as substance abuse, various anxiety disorders, and PTSD. ${ }^{44}$ 
Biological abnormalities seen in certain psychiatric conditions (e.g. inflammation, oxidative stress and perhaps changes in steroids or in biogenic amine activity) are associated with, and may cause, telomere shortening. ${ }^{45}$ Since such biochemical abnormalities cut across traditional psychiatric diagnoses ${ }^{46-48}$, telomere shortening may be related to specific biological processes or endophenotypes more than to specific diagnostic categories, although this remains to be adequately tested. This could help explain the inconsistency of LTL findings in specific diagnostic groups and the heterogeneity of findings among different diagnostic groups.

\section{Conclusion}

Psychosocial stress in childhood was associated with shorter telomere length in more than $90 \%$ studies, although other find negative association among them. It is also possible that certain psychiatric illnesses and telomeres length shortening are related to third factors common to both, rather than being directly causally related (e.g., poor sleep, poor nutrition, insufficient exercise, cigarette smoking) ${ }^{49-51}$ As it's a upcoming research area there is still a need for many longitudinal studies to find the association of childhood stress and its impact on life span.

\section{References}

[1]. Blascovich J, Mendes WB. Social psychophysiology and embodiment. In: Fiske, ST; Gilbert, DT, editors. The Handbook of Social Psychology. New York: Wiley; 2010.

[2]. Lazarus, RS, Folkman S. Stress, appraisal and coping. New York: Springer-Verlag; 1984.

[3]. Grippo AJ, Johnson AK. Stress, depression and cardiovascular dysregulation: a review of neurobiological mechanisms and the integration of research from preclinical disease models. Stress 2009;12(1):1-21.

[4]. McEwen BS. Physiology and neurobiology of stress and adaptation: central role of the brain. Physiol Rev 2007;87(3):873-904.

[5]. Wolkowitz OM, Reus VI, Mellon SH. Of sound mind and body: depression, disease, and accelerated aging. Dialogues Clin Neurosci 2011; 13:25-39.

[6]. Muezzinler A, Zaineddin AK, Brenner H. A systematic review of leukocyte telomere length and age in adults. Ageing Res Rev. 2013;12:509-19.

[7]. Epel ES. How "reversible" is telomeric aging? Cancer Prev Res (Phila). 2012; 5:1163-8.

[8]. Aubert G, Lansdorp PM. Telomeres and aging. Physiol Rev. 2008; 88:557-79.

[9]. Cawthon RM, Smith KR, O'Brien E, Sivatchenko A, Kerber RA. Association between telomere length in blood and mortality in people aged 60 years or older. Lancet. 2003; 361:393-5.

[10]. Gilley D, Herbert BS, Huda N, Tanaka H, Reed T. Factors impacting human telomere homeostasis and age-related disease. Mech Ageing Dev 2008;129(1-2):27-34.

[11]. Fitzpatrick AL, Kronmal RA, Gardner JP, Psaty BM, Jenny NS, Tracy RP et al. Leukocyte telomere length and cardiovascular disease in the cardiovascular health study. Am J Epidemiol 2007;165(1):14-21.

[12]. Martin-Ruiz C, Dickinson HO, Keys B, Rowan E, Kenny RA, Von Zglinicki T. Telomere length predicts poststroke mortality, dementia, and cognitive decline. Ann Neurol 2006;60(2):174-80.

[13]. Derradji H, Bekaert S, De Meyer T, Jacquet P, Abou-El-Ardat K, Ghardi M, Arlette M, Baatout S. Ionizing radiation-induced gene modulations, cytokine content changes and telomere shortening in mouse fetuses exhibiting forelimb defects. Dev Biol 2008;322(2):302-13.3

[14]. Bull C, Fenech M. Genome-health nutrigenomics and nutrigenetics: nutritional requirements or'nutriomes' for chromosomal stability and telomere maintenance at the individual level. Proc Nutr Soc 2008;67(2):146-56.

[15]. Rufer N, Brummendorf TH, Kolvraa S, Bischoff C, Christensen K, Wadsworth L, et al. Telomere fluorescence measurements in granulocytes and T lymphocyte subsets point to a high turnover of hematopoietic stem cells and memory $\mathrm{T}$ cells in early childhood. J Exp Med 1999;190(2):157-67.

[16]. Zeichner SL, Palumbo P, Feng Y, Xiao X, Gee D, Sleasman J, et al. Rapid telomere shortening in children. Blood 1999;93(9):2824-30.

[17]. Cameron N, Demerath EW. Critical periods in human growth and their relationship to diseases of aging. Am J Phys Anthropol 2002;(35):159-84.

[18]. Burns BJ, Phillips SD, Wagner HR, Barth RP, Kolko DJ, Campbell Y, Landsverk J. Mental health need and access to mental health services by youths involved with child welfare: a national survey. J Am Acad Child Adolesc Psychiatry 2004;43(8):960-70.

[19]. Melchior M, Moffitt TE, Milne BJ, Poulton R, Caspi A. Why do children from socioeconomically disadvantaged families suffer from poor health when they reach adulthood? A life-course study. Am J Epidemiol 2007;166(8):966-74.

[20]. Springer KW, Sheridan J, Kuo D, Carnes M. Long-term physical and mental health consequences of childhood physical abuse: results from a large population-based sample of men and women. Child Abuse Negl 2007;31(5):517-30. 3

[21]. Heim C, Newport DJ, Mletzko T, Miller AH, Nemeroff CB. The link between childhood trauma and depression: insights from HPA axis studies in humans. Psychoneuroendocrinology. 2008; 33:693-710.

[22]. Barreau F, Ferrier L, Fioramonti J, Bueno L. New insights in the etiology and pathophysiology of irritable bowel syndrome: contribution of neonatal stress models. Pediatr Res. 2007; 62:240-245.

[23]. Schweinhardt P, Sauro KM, Bushnell MC. Fibromyalgia: a disorder of the brain? Neuroscientist. 2008; 14:415-21.

[24]. Heim C, Nater UM, Maloney E, Boneva R, Jones JF, Reeves WC. Childhood trauma and risk for chronic fatigue syndrome: association with neuroendocrine dysfunction. Arch Gen Psychiatry.2009;66:72-80.

[25]. Charmandari E, Kino T, Souvatzoglou E, Chrousos GP. Pediatric stress: hormonal mediators and human development. Horm Res. 2003; 59:161-179.

[26]. Tietjen GE, Peterlin BL. Childhood abuse and migraine: epidemiology, sex differences, and potential mechanisms. Headache. 2011; 51:869-79.

[27]. Jones GT, Power C, Macfarlane GJ. Adverse events in childhood and chronic widespread pain in adult life: Results from the 1958 British Birth Cohort Study. Pain. 2009; 143:92-96.

[28]. Gluckman PD, Hanson MA. Living with the past: evolution, development, and patterns of disease. Science 2004; 305:1733-1736.

[29]. Brown DW, Anda RF, Tiemeier H, Felitti VJ, Edwards VJ, Croft JB, et al. Adverse childhood experiences and the risk of premature mortality. Am J Prev Med. 2009; 37:389-396. 
[30]. Slijepcevic P. Telomere length measurement by Q-FISH. Methods Cell Sci. 2001; 23:17-22.

[31]. Tyrka AR, Price LH, Kao HT, Porton B, Marsella SA, Carpenter LL. Childhood maltreatment and telomere shortening: preliminary support for an effect of early stress on cellular aging. Biol Psychiatry. 2010; 67:531-534.

[32]. Glass D, Parts L, Knowles D, Aviv A, Spector TD. No correlation between childhood maltreatment and telomere length. Biol Psychiatry. 2010; 68:e21-22.

[33]. Kananen L, Surakka I, Pirkola S, Suvisaari J, Lonnqvist J, Peltonen L, et al. Childhood adversities are associated with shorter telomere length at adult age both in individuals with an anxiety disorder and controls. PLoS One. 2010; 5:e10826.

[34]. Kiecolt-Glaser JK, Gouin JP, Weng NP, Malarkey WB, Beversdorf DQ, Glaser R. Childhood adversity heightens the impact of later-life caregiving stress on telomere length and inflammation. Psychosom Med. 2011; 73:16-22.

[35]. Surtees PG, Wainwright NW, Pooley KA, Luben RN, Khaw KT, Easton DF, et al. Life stress, emotional health, and mean telomere length in the European Prospective Investigation into Cancer (EPIC)-Norfolk population study. J Gerontol A Biol Sci Med Sci. 2011; 66:1152-1162.

[36]. Drury SS, Theall K, Gleason MM, Smyke AT, De Vivo I, Wong JY, et al. Telomere length and early severe social deprivation: linking early adversity and cellular aging. Mol Psychiatry. 2011 published online ahead of print May 18.

[37]. Entringer S, Epel ES, Kumsta R, Lin J, Hellhammer DH, Blackburn EH, et al. Stress exposure in intrauterine life is associated with shorter telomere length in young adulthood. Proc Natl Acad Sci U S A. 2011; 108:513-18.

[38]. Rizzo LB, Costa LG, Mansur RB, Swardfager W, Belangero SI, et al. The theory of bipolar disorder as an illness of accelerated aging: Implications for clinical care and research. Neurosci Biobehav Rev. 2014; 42C:157-169.

[39]. Gutierrez-Rodrigues F, Santana-Lemos BA, Scheucher PS, Alves-Paiva RM, Calado RT. Direct Comparison of Flow-FISH and qPCR as Diagnostic Tests for Telomere Length Measurement in Humans. PLoS One. 2014; 9:e113747. 10.1371/journal.pone.0113747.

[40]. Eitan E, Hutchison ER, Mattson MP. Telomere shortening in neurological disorders: an abundance of unanswered questions. Trends Neurosci. 2014; 37:256-63.

[41]. Aviv A, Hunt SC, Lin J, Cao X, Kimura M, Blackburn E. Impartial comparative analysis of measurement of leukocyte telomere length/DNA content by Southern blots and qPCR. Nucleic Acids Res. 2011; 39:e134.

[42]. Asok A, Bernard K, Roth TL, Rosen JB, Dozier M. Parental responsiveness moderates the association between early-life stress and reduced telomere length. Dev Psychopathol. 2013; 25:577-85

[43]. Adler N, Pantell MS, O'Donovan A, Blackburn E, Cawthon R, Koster A, et al. Educational attainment and late life telomere length in the Health, Aging and Body Composition Study. Brain Behav Immun. 2013; 27:15-21.

[44]. Lamers F, van Oppen P, Comijs HC, Smit JH, Spinhoven P, van Balkom AJ, et al. Comorbidity patterns of anxiety and depressive disorders in a large cohort study: the Netherlands Study of Depression and Anxiety (NESDA). J Clin Psychiatry. 2011; 72:341-8.

[45]. Wolkowitz OM, Mellon SH, Epel ES, Lin J, Dhabhar FS, Su Y, Reus VI, et al. Leukocyte telomere length in major depression: correlations with chronicity, inflammation and oxidative stress--preliminary findings. PLoS One. 2011a; 6:e17837. 10.1371/journal.pone.0017837.

[46]. Smyth AM, Lawrie SM. The Neuroimmunology of Schizophrenia. Clin Psychopharmacol Neurosci. 2013; 11:107-117.

[47]. Rosenblat JD, Cha DS, Mansur RB, McIntyre RS. Inflamed moods: A review of the interactions between inflammation and mood disorders. Prog Neuropsychopharmacol Biol Psychiatry. 2014; 53C:23-34.

[48]. Pandya CD, Howell KR, Pillai A. Antioxidants as potential therapeutics for neuropsychiatric disorders. Prog Neuropsychopharmacol Biol Psychiatry. 2013; 46:214-23.

[49]. Puterman E, Epel ES, Lin J, Blackburn EH, Gross JJ, Whooley MA, Cohen BE. Multisystem resiliency moderates the major depression-telomere length association: findings from the Heart and Soul Study. Brain Behav Immun. 2013; 33:65-73.

[50]. Prather AA, Gurfein B, Moran P, Daubenmier J, Acree M, Bacchetti P, et al. Tired telomeres: Poor global sleep quality, perceived stress, and telomere length in immune cell subsets in obese men and women. Brain Behav Immun. 2014 10.1016/j.bbi.2014.12.011

[51]. Shalev I, Entringer S, Wadhwa PD, Wolkowitz OM, Puterman E, Lin J. Stress and telomere biology: A lifespan perspective. Psychoneuroendocrinology. 2013; 38:1835-42. 